\title{
What does an effective teacher of writing do that makes a difference to student achievement?
}

MURRAY GADD

\section{KEY POINTS}

- To generate greater than expected learner gains in writing, it is necessary

to effectively implement teacher actions related to all dimensions of effective practice (expectations; learning goals; learning tasks; direct instruction; responding to students; motivation and challenge; organisation and management; self-regulation).

- Effective implementation of teacher actions related to three dimensions (learning tasks, direct instruction, and self-regulation) is probably most critical if greater than expected learner gains in writing are to be made.

- Teachers' instructional actions are most likely to be effective if they:

- $\quad$ are regarded as purposeful by students

- include meaningful opportunities for student involvement

- $\quad$ are explicit and direct

- $\quad$ are differentiated in terms of student needs

- lead to opportunities for independence and self-regulation by students. 
This article, based on an 18-month study of effective writing instruction amongst Year 5 to 8 students, concludes that effective implementation of three dimensions of effective practice (learning tasks; direct instruction; selfregulation) are probable key levers in generating greater than expected learner gains in writing. It further concludes that teachers' instructional actions are most likely to be effective if they are regarded as purposeful by students, include meaningful opportunities for student involvement, are explicit and direct, are differentiated in terms of student needs, and lead to opportunities for independence and self-regulation by students as developing writers. It provides illustrations of what these actions look like in authentic classrooms.

\section{Introduction}

Being proficient at writing is essential for students' success, both during and beyond their schooling. It is not only an integral part of their schooling but also their everyday lives as they participate in the world of texting, blogging, and social media. But students rarely develop proficiency as writers at school without effective teacher instruction (Graham, Capizzi, Harris, Hebert \& Morphy, 2014). In her report to the Ministry of Education on quality teaching for diverse learners, Alton-Lee (2003) concludes that "Quality teaching ... is the most influential point of leverage on student outcomes" (p. 2).

There is a strong need to raise the proficiency level of many New Zealand students as developing writers, especially as they move from junior to middle and senior primary school. In the Ministry of Education's most recent statement on writing achievement in relation to National Standards (https://www. educationcounts.govt.nz/statistics/schooling/nationalstandards/National_Standards), the Ministry reports a relatively high level of underachievement (26.5\%) for Years 1 to 4 students and an even higher level (30.7\%) for Years 5 to 8 students. Hence there is also a strong need to continue investigating what effective teacher instruction for all primary-age students, but particularly Years 5 to 8, should look like.

This article, based on the author's 18 -month investigation of the instructional writing practice of nine exemplary teachers of Years 5 to 8 students in the New Zealand context (Gadd, 2014), places the findings of the study within the context of classroom practice and inquires: What does an effective teacher of writing do that makes a difference? For the purpose of the study, "being effective" relates to teachers being able to generate a positive impact on student outcomes, particularly academic outcomes (Pianta $\&$ Hamre, 2009).

Although the findings are contextualised in Year 5 to 8 classrooms, it is anticipated that they will apply to teachers of any primary-age students, particularly in the New Zealand context. As concluded towards the end of the study, "What is good for some is good for all” (Gadd, 2014, p. 184).

\section{Identifying some critical aspects of effective practice}

Many researchers have investigated and reported on what constitutes effective teacher instruction in writing (for example, Graham et al., 2014; Grossman, Loeb, Cohen \& Wyckoff, 2013; Parr \& Limbrick, 2010). This has led to widespread agreement that teachers employ a strategic blend of dimensions of effective practice to enhance learning. Effective practice is complex and involves many teacher decisions about how it should be undertaken. Hall and Harding (2003) suggest that it is "an intelligent weaving together" (p. 42) of different dimensions.

A wide and iterative reading by the author of international research literature (post-1990) on effective writing instruction indicated that teaching actions relating principally to the following eight dimensions need to be woven together in order to promore effectiveness:

- expectations (the vision of achievement that teachers hold and communicate to students)

- learning tasks (what teachers do and think about as they devise tasks and topics for and with students)

- learning goals (what teachers do and think about as they develop learning goals for and with students) 
- direct instruction (the instructional actions, such as demonstrating and questioning, that teachers consider and use when providing instruction)

- responding to students' work (how teachers give feedback and feed-forward information to students, the nature of this information, and how students use it)

- motivating and challenging students (what teachers do to motivate students as writers and challenge them cognitively at a level appropriate to their potential)

- organisation and management (what teachers do to organise, differentiate, and manage instructional lessons effectively)

- self-regulation (actions that teachers take to give students a sense of ownership or responsibility about what they are doing to develop as independent writers).

But the author (like some of the researchers cited above) wondered whether any of these dimensions could be regarded as critical within the complex process of effective writing instruction.

\section{Research design}

A range of quantitative and qualitative research actions was utilised to undertake the investigation. First, a group of appropriate teacher and student participants was selected. All selected teachers $(n=9)$ were regarded as "exceptional" (a term borrowed from Creswell, 2008, p. 216) in that all their classes had achieved significantly greater than the nationally expected rate of progress in writing over the preceding 2 or 3 years.

These teachers were observed leading three writing lessons over 12 months (on any aspect of the writing process they deemed necessary) and were interviewed about their practice on each occasion. In addition, selected students in each classroom were interviewed about their learning. Each teacher also used the asTTle writing tool (version 4) to calculate learner gains (in relation to national norms) over the year (University of Auckland, 2005).

Data from the lesson observations, the interviews with teachers and students, and the learner gains calculations were subsequently entered into a statistical analysis program and used to identify non-parametric correlations between each of the dimensions and positive outcomes for students. Did any of the dimensions of effective practice appear to be critical within the proviso that all are necessary for positive student outcomes? Any that appeared to be critical were to be referred to as foreground dimensions. ${ }^{1}$

\section{What really matters}

Two dimensions of effective practice emerged statistically as probable foreground dimensions. There was a significant correlation (using Spearman's rho) between high learner gains and teacher effectiveness for learning tasks $\left(r_{s}=.73\right.$, $p<.05)$ and for direct instruction $\left(r_{s}=.67, p<.05\right)$. Selfregulation was also nominated as a probable foreground dimension in that it was the dimension with the greatest degree of operational variability between those teachers whose students made the greatest learner gains and the other participating teachers.

These findings suggest that the tasks that teachers establish for and with their students, and the instructional acts (such as demonstrating and questioning) they use to support their students, really matter. They also suggest the particular importance of teachers working with their students in ways that lead to independence and selfmanagement.

Direct causal links were not claimed in the study, but strong levels of association were suggested. As explained by Grossman and colleagues (2013), although nonparametric analysis cannot indicate direct causality, it can "establish a credible hypothesis that ... aspects of classroom practice may meaningfully improve student achievement" (p. 457).

However, it was also understood that the apparent effectiveness of any particular dimension may well be contingent on its interconnectedness with others in the same context (Hall \& Harding, 2003). Particular attention might need to be given to strategic implementation of the three foreground dimensions (learning tasks; direct instruction; self-regulation), but effective teachers attend to strategic implementation of all eight dimensions in combination if they are to generate greater than expected learner gains. Strategic implementation of all dimensions is necessary, but it is more critical for some than for others.

The remainder of the article describes and discusses what strategic implementation of the three foreground dimensions looks like in a range of authentic classrooms in which teachers taught and encouraged students to plan, craft, re-craft, and present extended fiction and non-fiction texts over time.

\section{What does strategic implementation of the foreground dimensions look like?}

Having calculated these initial quantitative results, the subsequent task was to analyse observation and interview transcripts further so as to inquire into examples of, and implications for, classroom practice: What do these results look like with regard to the practice of particularly effective teachers, especially related to the three foreground dimensions of learning tasks, direct instruction, and self-regulation? 
Note was especially taken of practice in classrooms where students made particularly strong learner gains; namely, the mean gain in the classroom for "all students" exceeded expected gain by at least 60 asTTle writing score points (in relation to score expectations for each year cohort). This was the case in four (out of nine) classrooms.

\section{Learning tasks}

Learning tasks can be student or teacher generated. Within the context of instructional writing, they can be single writing tasks for all students or multiple writing tasks for students to select from; they can be worked on by students at varying times or simultaneously; they can be designed to generate one intended outcome or a range of possible outcomes; they can be designed as interactive or cooperative tasks or tasks for individual students; and involvement in them can be self-selected or teacher directed.

A closer investigation into what effective teachers were doing in this study indicated evidence of four key properties of effective task orientation-tasks need to be purposeful and motivating for students; they need to challenge students at an appropriate level; they need to link closely to identified learning goals; and students need to be involved in the selection and construction of the tasks.

Implementation of these properties has several implications for teachers.

1. Effective teachers select writing topics carefully and strategically so as to engage, motivate and challenge students (Gadd \& Parr, 2016; Lodewyk, Winne \& Jamieson-Noel, 2009).

Most topics that were selected across the study related to either the students' own experiences, understandings, and interests (Calkins, 1994), or the cross-curriculum findings and challenges that emerged from classroom inquiry (Wood, 2003).

One teacher suggested that teachers and students "have to seize the moment...because topic is so essential...I find the best writing is the writing that's, you know, got real purpose". The teacher did not have a predetermined plan of topics for writing "because that would not allow us, as a class, to go off and write on the things that we want to write about...[Topics] will arise according to kids' experiences and needs and interests...”. The teacher added that "having something to say... something to write about...is of paramount importance to me as a teacher of writing”.

2. Effective teachers involve students in the selection and construction of writing tasks whenever possible (Gadd \& Parr, 2016).

Perry and Drummond (2002) contend that "when students have choices, they are typically more interested in and committed to activities, and committed learners are more likely to increase effort and persist when difficulties arise" (p. 306).

An example of student involvement in task construction involved a teacher inquiring of his or her students, "What things have we been doing lately that we might write about? Have a think..." When the students decided on a possible topic of interest the teacher asked about purpose and audience, "Who might want to read about this?" and "What do you want to tell them about this? Would you be writing to report or to persuade or to recount...?" The students wrote because they had something to say (which they had decided on) and the text type to be utilised emerged from the topic rather than the other way around. The topic (and its purposerelated task) drove the lesson.

A more low-key way of involving students in task construction is to ensure that most teacher-selected writing topics are open-ended in nature, as most of these teachers did. For example, personal experience topics such "What really annoys me ...", "When I was dared to do something ..." or "The first time I ever ..." enabled students to write from the perspective of personal interests, understandings, or experiences, but within broad parameters established by the teacher.

Not all teacher-selected topics can be open-ended of course. If, for example, the task is to report on a particular scientific discovery that the class has made, it is appropriate that the topic be closed.

3. Effective teachers ensure that writing tasks are underpinned by clear and precise learning goals which students are involved in developing (Lodewyk et al., 2009).

Operationally, this often involved the teacher and students collaboratively identifying the cognitive demands in a writing task and deciding together what writing strategies or skills were needed to meet those demands and undertake the task successfully. Mostly, some teacher prompting of required strategies or skills was needed.

Lessons often began with extended discussion about the task and its possible content before segueing into discussion of the aligned learning goal/s: "So what are we going to have to be good at as writers to do this task well?" Just as discussion of the text type emerged from discussion of the task (see the previously cited teacher example), so discussion of the aligned learning goal/s emerged from discussion of the task.

\section{Direct instruction}

For the study, direct instruction was defined as the act of "providing information that fully explains the concepts 
and procedures that students are required to learn as well as learning strategy support that is compatible with human cognitive architecture" (Kirschner, Sweller, \& Clark, 2006, p. 75). This requires teachers to scaffold for students to help them achieve success for tasks that are deemed to be challenging for them (Wood, Bruner, \& Ross, 1976).

Scaffolding effectively in instructional writing might involve (for example) ensuring that students are aware of actions necessary for successful completion of the task, helping them build possible content for their text, demonstrating or modelling expected outputs for them, questioning or prompting them about the content of their texts, or even providing them with a structure to write within (Hmelo-Silver, Duncan, \& Chinn, 2007).

But scaffolding should only be provided for those who actually require it and at the appropriate time. Differentiated levels of direct instruction are necessary for students - some will get frustrated if they receive insufficient instruction; others will get bored if they receive excessive instruction. Ascertaining the level of instructional support needed by diverse students for diverse tasks is an important skill required by effective teachers (Englert, Raphael, Anderson, Anthony \& Stevens, 1991).

Three key properties of direct instruction emerged from classroom observations and interviews across the study-learning outcomes need to be demonstrated clearly to students; key aspects of classroom discourse (especially questioning) need to be carefully attended to; direct instruction needs to be differentiated according to student needs.

Implementation of these properties has the following implications for teachers.

1. Effective teachers demonstrate learning processes and outcomes to students (Regan \& Berkeley, 2012; Schunk, 2003).

To do this, they can use both active and receptive modes. Active demonstrating (often referred to as shared writing) involves the teacher composing a text collaboratively with students; receptive demonstrating involves the teacher instructing from previously created texts.

Both modes of demonstrating are important, but active demonstrating was the mode most strongly associated with teachers whose students made the greatest learning gains in the study. All teachers used receptive demonstrating - for example, some used it to teach the structure and text features of non-fiction writing through deconstruction of exemplars-but only those teachers whose students made the greatest learning gains used active demonstrating as well.

When students needed to be introduced to new or challenging concepts or appeared to be unsure of learning points during active demonstrating, teachers used "think alouds" to demonstrate the concept or point (Ness \& Kenny, 2016). While the teacher articulated an inner dialogue about how to solve a writing problem (such as selecting the most appropriate detail or word in a text), students watched and listened in order to be able to transfer the demonstrated skill to their own writing.

Through active demonstrating, teachers not only instructed students at the word, sentence, or whole text level, or a combination of all, but they also revealed themselves to be active members of a writing community and to be problem-solvers and risk-takers as mistakes were made and corrected.

2. Effective teachers question, prompt, and respond effectively for deep, metacognitive, text-related thinking by their students (Dyson, 2002).

Rich discourse (particularly questioning) is at the heart of all teacher-student interactions about writing, whether it occurs in one-to-one, small group, or large group contexts, during demonstrating or feedback sessions, or while students are planning, crafting, re-crafting, or presenting their texts.

Teachers need to think about the level of demand in their questions (Cotton, 1988). Questions can be categorised into low-, medium-, and high-demand types, with the level of demand based on the level of cognitive challenge and complexity within the question (Bloom, 1956). High-cognitive-demand questions are those that require students to analyse, evaluate, and synthesise textrelated issues and think deeply and metacognitively about them.

During the study, it was noted that teachers whose students made the greatest learning gains asked three times as many high-cognitive-demand questions as did other teachers. These teachers focused more on asking "how?" and "why?" questions (such as, "Why do you want to use personification in your description? How will it help the reader get a clear picture in their mind?') rather than "what?" questions (such as, "What is personification?").

\section{Effective teachers differentiate their instruction in order to address diverse and changing needs amongst students as developing writers. They constantly inquire, "Who needs what teaching and when?"}

Grouping is at the heart of differentiated instruction (Paratore \& McCormack, 2009). If needs (rather than ability levels) are to be addressed, grouping needs to be flexible (Schum \& Avalos, 2009). Flexible groupsoften referred to as 'writing workshops' - are formed by teachers analysing student texts (usually in relation to shared criteria) and bringing together several learners with similar instructional learning needs. 
Teachers across the study rarely undertook direct writing instruction with the whole class; they worked instead with groups for short periods. A typical pattern was for the teacher to work initially with the whole class (establishing and engaging students in a topic and task; generating possible content for the task; sometimes developing criteria for successful completion of the task) before moving many students off to write independently while they worked with a group.

This sometimes involved demonstrating expected writing outputs to a group of (often low-achieving) students and helping them start to write their text. It often involved bringing a group together (generally mixed ability) to share and discuss the writing that they had undertaken so far and act as a responsive audience for each other.

More often, it involved undertaking a "workshop" on an identified need (such as "adding detail" or "making changes to writing') that was common to the group. The teaching point was always identified at the beginning of the workshop, the teaching and learning was always contextualised within a text that one of the students in the group had generated, and the other students in the group were always required to apply new learning acquired during the workshop to their text as soon as possible.

While the teacher interacted with a small group, other students worked independently at the stage of the writing process (planning; crafting; re-crafting; presenting) that was most appropriate for them.

The concept of differentiated instruction was critical for teachers across the study. As one explained:

I've got ... almost beginning writers through to some really quite advanced writers in my [Year 7] class this year. One size just doesn't fit all ... I have to look for ways of doing things that allow each of my kids to learn or make progress at their own level ... Otherwise I'm going to lose some of them ... and I don't just mean my target kids ...

\section{Self-regulation}

The concept of students developing as independent, motivated, metacognitive and self-regulated learners has long been considered key to affecting learner gains (Perry, Hutchinson, \& Thauberger, 2008). Within the context of instructional writing, students demonstrate selfregulatory learning habits when they (for example) select and plan their own topics and tasks, set and monitor themselves against personal learning goals, assume responsibility for seeking and using support necessary for addressing identified challenges, and are able to reflect on and articulate what they are doing, thinking about and achieving as they write or learn about writing (Perry \& VandeKamp, 2000).
With regard to self-regulation, this study focused on the actions that effective teachers take to promote selfregulatory habits by students. Gibbs and Poskitt (2010) conclude that students "who have been taught how to use self-regulation processes and are provided with opportunities to use them, demonstrate high levels of engagement and achievement" (p. 20).

Three key actions emerged from observations and interviews across the study - teachers need to encourage students to write on self-selected topics outside instruction writing time, work collaboratively with others on writing tasks on occasions, and take responsibility for seeking instructional support as appropriate.

Implementation of these selected actions has the following implications for teachers.

\section{Effective teachers provide opportunities for independent (as well as instructional) writing by students.}

As an instructional approach, independent writing principally involves students writing for self-selected purposes and on self-selected topics and at times and places selected by the student. The intended audience may, or may not, include the teacher (Perry \& Drummond, 2002).

As the teacher is expected to provide little guidance or support for most students on "what" and "how" to write during independent writing, the teacher must ensure that students hold mastery of the problem-solving and selfmonitoring strategies required for successful outputs to be generated (Perry \& Drummond, 2002).

Teachers across the study consistently encouraged their students to write independently by implementing variations of the above guidelines. Some timetabled independent writing sessions; others merely encouraged their students to write in their own time. Some allowed for total selfselection of topics; others offered topics that students could choose from if they wished. Some encouraged use of a "writer's notebook" (Calkins, 1994)_electronic or hard copy-in which students noted possible topics for writing and wrote on imaginative, real-life, and factual topics that they were excited about. Students' independent writing was not assessed as such, but teachers were always willing to respond to writing (if asked), or help students prepare it for a wider audience (if asked), or both.

But no matter how they implemented independent writing, teachers were committed to encouraging their students to write for themselves whenever possible. As one stated:

I want writing to be a real-life thing for my students...It's not just something you do between 9 and 10; it's something you do because you've got something to say... and you want to get it out of you... Um, I think my students like writing 
cause they know they can say whatever they want (within reason!) and they know that I'm always happy to read their writing and talk to them about it ... I want them to think of themselves as writers and understand that writing isn't just something you do in writing time.

\section{Effective teachers encourage students to write collaboratively from time to time.}

Pairs or groups for collaboration can be similar or mixed ability. Some teachers formed groups around the pedagogical concept of tuakana-teina in which "more expert" students are paired with "less expert" students to foster expertise and empathy within students (Winitana, 2012).

As a representative example of teachers encouraging students to write collaboratively, one teacher (as part of a social studies inquiry) suggested that his/her students work in buddy-pairs to ascertain the skills needed for writing a newspaper report from known examples, plan the content of a report, and devise a headline for the report. Each pair was subsequently encouraged to articulate to others what they had learnt about writing a report so as to begin to build a collegial understanding of effective newspaper writing skills.

3. Effective teachers encourage students to assume responsibility for self-monitoring their progress and seeking the support and assistance they perceive as necessary to overcome problems and address challenges in their writing.

Being proficient at this requires students to understand fully what they are attempting to achieve in any particular writing task and being able to recognise problems and challenges that emerge in their writing. Students need to regard themselves as writers and be selfaware of their cognitive strengths and needs in writing (Perry \& VandeKamp, 2000). "Needs" include those to be addressed to be successful at the writing task as well as needs that are personal to them.

Several teachers (especially those whose students made the greatest learner gains) were committed to handing degrees of responsibility for seeking support and assistance to their students. Some invited rather than directed students to attend workshops they were implementing. Others organised workshops around the strategies and skills required for successful completion of a task and encouraged students to "book in" for those they needed to attend.

The conversation below (between a teacher and his/ her class) represents an example of teachers guiding their students toward assuming some responsibility for support and assistance as needed.
Teacher: When I looked at your draft writing yesterday, I felt that some of you hadn't introduced your topic as clearly as you could have? Anyone feel that was a problem for them?

[Several hands are raised.]

Teacher: OK ... let's just recall what we decided about writing a good introduction for our instructions ...

[Prolonged discussion.]

Teacher: ... Now get out your introductions from yesterday everyone.

[Students place their texts on their desks.]

Teacher: Um ... my feeling is that quite a few of you found it difficult to come up with a good hook ... Now read back the introduction that you wrote yesterday and decide whether you're happy with your hook. If you're not, you can come down on the mat with me in a while cause I'm going to run a bit of a workshop on this ... You have a read and you decide whether you need to be on the mat or not ... No point in being here if you can just go on with your writing ... If you're not sure, you might want to talk this through with your writing buddy ... Try and be honest with yourselves ...

The teacher was guiding the students towards assuming some responsibility for identifying problems and challenges so that they could assume greater responsibility when writing independently.

\section{Conclusion}

The purpose of this article has been to place the quantitative and qualitative findings of the author's study of effective literacy practice (Gadd, 2014) within the context of authentic classrooms: So what does an effective teacher do that makes a difference for learner gains? By analysing the practice of a group of exemplary teachers over time, three dimensions of effective practice emerged as probable key levers in generating greater than expected learner gains (learning tasks; direct instruction; selfregulation).

This initial finding led to a closer examination of the practice of teachers, but particularly those whose students made the greatest learner gains and particularly around the three dimensions that had been identified as potentially critical. Deeper analysis of observation and interview transcripts generated a conclusion that teachers' instructional actions are most likely to be effective if they are regarded as purposeful by students, include meaningful opportunities for student involvement, are explicit and direct, are differentiated in terms of student needs, and lead to opportunities for independence and self-regulation by students as developing writers. This 
article provides illustrations of what these actions look like in authentic classrooms.

It is not implied that teacher actions outside these nominated parameters are unimportant. For example, all teachers in the study responded positively and constructively (in varying ways) to students' writing efforts, and almost all ensured that students got sufficient opportunities to write extended texts (rather than undertake skill-building exercises) during lessons. But the actions above have been focused on because of their links with particular foreground dimensions and because they were strongly evident within the practice of teachers whose students made the greatest learner gains.

Neither is it implied that attending to these teacher actions as discrete entities will directly affect learner gains. They must be regarded as part of an integrated whole within the complexity of effective practice. As discussed previously, the apparent effectiveness of any dimension or instructional action may well be contingent on its interconnectedness with other dimensions and actions within the same pedagogical context (Hall \& Harding, 2003).

There is a range of teacher-related variables that influence student achievement in writing. These include the level of literacy content knowledge that teachers hold, their relationships with and knowledge of students as learners, their beliefs about literacy teaching and learning, and their personal disposition and professional aptitudes for teaching and learning. But this article has focused on arguably the most important variable-what teachers do that makes a difference (Alton-Lee, 2003). It is anticipated that it will assist teachers to understand what needs to be in place for greater-than-expected learner gains in writing.

\section{Note}

I Refer to the Methodology chapter (pp.5I-90) of Gadd (2014) for more details of the investigation's research design, especially issues of reliability and validity related to gathering, aggregating, analysing, and interpreting data.

\section{References}

Alton-Lee, A. (2003). Quality teaching for diverse students in schooling: Best evidence synthesis. Wellington: Ministry of Education.

Bloom, B. (1956). Taxonomy of educational objectives: The classification of educational goals: Handbook I. Cognitive domain. New York, NY: Longmans Green.

Calkins, L. M. (1994). The art of teaching writing. Portsmouth, NH: Heinemann.
Cotton, K. (1988). Classroom questioning (School Improvement Research Series). Retrieved from http://educationnorthwest. org/sites/default/files/classroom-questioning.pdf

Creswell, J.W. (2008). Educational research: Planning, conducting and evaluating quantitative and qualitative research (3rd Ed.). Upper Saddle River, NJ: Pearson Merrill Prentice Hall.

Darling-Hammond, L. (1999). Teacher quality and student achievement: A review of state policy evidence. Washington, DC: Centre for the Study of Teaching and Policy.

Dyson, A. H. (2002). A Bakhtinian buzz about teacher talk: Discourse matters in "What difference does difference make?" English Education, 35(1), 6-20.

Englert, C. S., Raphael, T. E., Anderson, L. M., Anthony, H. M., \& Stevens, D. D. (1991). Making strategies and self-talk visible: Writing instruction in regular and special education classrooms. American Educational Research Journal, 28(2), 337-372. https://doi.org/10.3102/00028312028002337

Gadd, M. (2014). What is critical in the effective teaching of writing? A study of the classroom practice of some year 5-8 teachers in the New Zealand context. Unpublished doctoral thesis, University of Auckland.

Gadd, M. \& Parr, J. M. (2016). It's all about Baxter: Task orientation in the effective teaching of writing. Literacy, 50(2), 93-99. https://doi.org/10.1111/lit.12072

Gibbs, R., \& Poskitt, J. (2010). Student engagement in the middle years of schooling (Years 7-10): A literature review. Wellington: Ministry of Education.

Graham, S., Capizzi, A., Harris, K. R., Hebert, M., \& Morphy, P. (2014). Teaching writing to middle school students: A national survey. Reading and Writing, 27(6), 1015-1042. https://doi.org/10.1007/s11145-013-9495-7

Grossman, P. L., Loeb, S., Cohen, J., \& Wyckoff, J. (2013). Measure for measure: The relationship between measures of instructional practice in middle school English language arts and teachers' valued-added scores. American Journal of Education, 119, 445-470. https://doi.org/10.1086/669901

Hall, K., \& Harding, A. (2003). A systematic review of effective literacy teaching in the 4 to 14 age range of mainstream schooling. London, UK: Social Science Research Unit, Institute of Education.

Hmelo-Silver, C., Duncan, R., \& Chinn, C. (2007). Scaffolding and achievement in problem-based and inquiry learning: A response to Kirschner, Sweller, and Clark (2006). Educational Psychologist, 42(2), 99-107. https://doi. org/10.1080/00461520701263368

Kirschner, P. A., Sweller, J., \& Clark, R. E. (2006). Why minimal guidance during instruction does not work: An analysis of the failure of constructivist, discovery, problembased, experiential and inquiry-based learning. Educational Psychologist, 41(2), 75-86. https://doi.org/10.1207/ s15326985ep4102_1

Lodewyk, K. R., \& Winne, P. H. (2005). Relations among the structure of learning tasks, achievement and changes in self-efficacy in secondary students. Journal of Educational Psychology, 97(1), 3-12. https://doi.org/10.1037/00220663.97.1.3 
Lodewyk, K. R., Winne, P. H., \& Jamieson-Noel, D. L. (2009). Implications of task structure on self-regulated learning and achievement. Educational Psychology, 29(1), 1-25. https://doi. org/10.1080/01443410802447023

Ness, M. \& Kenny, M. (2016). Improving the quality of thinkalouds. The Reading Teacher, 69(4), 453-460. https://doi. org/10.1002/trtr.1397

Paratore, J. R., \& McCormack, R. L. (2009). Grouping in the middle and secondary grades: Advancing content and literacy knowledge. In K. D. Wood \& W. E. Blanton (Eds.), Literacy instruction for adolescents: Research-based practice (pp. 420-441). New York, NY: The Guilford Press.

Parr, J. M., \& Limbrick, L. (2010). Contextualising practice: Hallmarks of effective teachers of writing. Teaching and Teacher Education, 26(3), 583-590. https://doi.org/10.1016/j. tate.2009.09.004

Perry, N. E., \& Drummond, L. (2002). Helping young students become self-regulated researchers and writers. The Reading Teacher, 56(3), 298-310.

Perry, N. E., Hutchinson, L., \& Thauberger, C. (2008). Talking about teaching self-regulated learning: Scaffolding student teachers' development and use of practices that promote self-regulated learning. International Journal of Educational Research, 47(2), 97-108. https://doi.org/10.1016/j. ijer.2007.11.010

Perry, N. E., \& VandeKamp, K. J. O. (2000). Creating classroom contexts that support young children's development of self-regulated learning. International Journal of Educational Research, 33(7), 821-843. https://doi. org/10.1016/S0883-0355(00)00052-5

Pianta, R. C., \& Hamre, B. K. (2009). Conceptualization, measurement and improvement of classroom processes: Standardized observation can leverage capacity. Educational Researcher, 38(2), 109-119. https://doi. org/10.3102/0013189X09332374
Regan, K., \& Berkeley, S. (2012). Effective reading and writing instruction: A focus on modelling. Intervention in School and Clinic, 47(5), 276-282. https://doi. org/10.1177/1053451211430117

Schumm, J. S., \& Avalos, M. A. (2009). Responsible differentiated instruction for the adolescent learner. In K. D. Wood \& W. E. Blanton (Eds.), Literacy instruction for adolescents: Research-based practice (pp. 144-169). New York, NY: The Guilford Press.

Schunk, D. H. (2003). Self-efficacy for reading and writing: Influence of modelling, goal setting and self-evaluation. Reading and Writing Quarterly, 19, 159-172. https://doi. org/10.1080/10573560308219

University of Auckland (2005). asTTle: Assessment tools for teaching and learning (version 4). Wellington: University of Auckland/Ministry of Education.

Winitana, M. (2012). Remembering the deeds of Maui: What messages are in the tuakana-teina pedagogy for tertiary educators? Mai Journal: A New Zealand Journal of Indigenous Scholarship, 1(1), 29-37.

Wood, K.D. (2003). New dimensions of content area literacy: Not just for secondary teachers anymore. California Reader, 36, 12-17.

Wood, D., Bruner, J.S., \& Ross, G. (1976). The role of tutoring in problem-solving. Journal of Child Psychology and Psychiatry, 17(2), 89-100. https://doi. org/10.1111/j.1469-7610.1976.tb00381.x

Murray Gadd is an independent literacy consultant and researcher. He holds a PhD from the University of Auckland and currently acts as an Honorary Research Fellow for the university.

Email:mgadd@xtra.co.nz 